\title{
Clinical isolates of Tritrichomonas foetus in bulls in Wyoming, South Dakota and Montana, USA
}

\author{
Yinzhu Jin ${ }^{1,2}$, Aifang Du ${ }^{3}$ and Chaoqun Yao ${ }^{1,4^{*}}$ (D)
}

\begin{abstract}
Background: Several Tritrichomonas species have been found in mammalian hosts. Among these trichomonads $T$. foetus is often found in the urogenital tract of cattle and the gastrointestinal tract of the domestic cat, resulting in sexually transmitted bovine trichomonosis and fecal-orally transmitted feline trichomonosis, respectively. The aims of the current study were to molecularly characterize clinical isolates of T. foetus in cattle populations in Wyoming, South Dakota, and Montana of the United States of America and to phylogenetically analyze Tritrichomonas species of mammalian hosts.

Results: DNA sequencing of rRNA genes showed over 99\% identity of the newly described isolates to other bovine isolates. Further, T. foetus isolates of various mammalian hosts originated in different geographic regions worldwide were clustered into two well-defined clades by phylogenetic analysis of rRNA and cysteine protease 2 genes. Clade I consisted of isolates originated from cattle, pig, and human whereas clade || contained isolates of cat and dog.

Conclusion: It is concluded that all mammalian Tritrichomonas spp. apparently belong to T. foetus. Analysis of more sequences is warranted to support this conclusion.
\end{abstract}

Keywords: Tritrichomonas foetus, Trichomonosis, rRNA gene, Cysteine protease, Cattle

\section{Background}

Tritrichomonas foetus is a trichomonad protozoan of worldwide distribution in cattle populations in both developed and developing countries. It is often found in the urogenital tract of bovine hosts whose reproduction is mainly achieved by natural service of coitus. Interestingly, the protozoan is more effectively transmitted from an infected male to a susceptible female than from a cow to a bull. $95 \%$ of susceptible nulliparous cows became infected after a single mating with a $T$. foetus-positive bull [16]. In contrast, it took three to six times of mating for T. foetus-negative Hereford bulls of age 4-6 years to become $T$. foetus positive when they were allowed to mate with $T$. foetus-positive heifers.

\footnotetext{
* Correspondence: chyao@rossvet.edu.kn

${ }^{1}$ Department of Veterinary Sciences, University of Wyoming, Laramie, WY 82070, USA

${ }^{4}$ Department of Biomedical Sciences and One Health Center for Zoonoses and Tropical Veterinary Medicine, Ross University School of Veterinary Medicine, P.O. Box 334, Basseterre, St. Kitts and Nevis

Full list of author information is available at the end of the article
}

Furthermore, one three-year old bull became positive only after nine times of mating whereas the other still remained negative afterwards [2]. A bull usually becomes a lifetime carrier once being infected whereas a cow naturally clears infection in a few months postinfection [26]. Occasionally a cow remains T. foetus positive for a longer period of time. For example, she was still positive 22 months after infection or 9 weeks after her having given birth to a calf post a normal pregnancy $[1,17]$.

Bovine trichomonosis is endemic in the United States of America (USA) especially in the states west of the Mississippi River [28]. The control and eradication method of bovine trichomonosis that has been proven most effective is artificial insemination (AI). AI has been being practiced throughout the European Union (EU) where $T$. foetus infection in cattle is practically nonexistent. For example, only two cases of bovine trichomonosis were found in the United Kingdom (UK) in 20 years [22]. We have recommended AI as the top choice followed by culling $T$. foetus-positive bulls to curtail its endemic in the USA $[8,26]$. However, not all US cattle 
farmers are practicing AI or are willing to perform AI due to facilities or cost effectiveness, or various constraints of their operations. In a questionnaire study carried by us in Wyoming in the Spring 2011, only 2.1\% of Wyoming cattle producers used AI and another 36.7\% would consider AI in the future [8]. The current measure of testing all bulls for T. foetus and culling T. foetuspositive ones had led to a gradual and steady decrease in bovine prevalence in Wyoming from 2.69\% in 1999, the year immediately prior to regulation enforcement, to $0.21 \%$ in year 2010 [28]. The control method appeared effective, but there was still a long way to control and eventually to eradicate bovine trichomonosis in the USA.

In addition to cattle, $T$. foetus also infects the domestic cat. Different from that in cattle, the predilection site of feline infection is the gastrointestinal tract which may lead to diarrhea, often a chronic one [30]. Nevertheless, a different species, i.e., T. blagburni, had been proposed for the protozoan in the feline host [24], although the name had not been widely accepted yet. In addition, $T$. suis in swine host and T. foetus in cattle were considered synonymous $[10,20]$. T. foetus was suggested as a valid name for the species due to its wide use for being the etiological agent of bovine trichomonosis even though $T$. suis was a senior synonym to T. foetus [18]. Furthermore, $T$. foetus bovine isolate had been occasionally reported in human $[25,29]$. There is paucity and confusion about Tritrichomonas species infecting these mammalian hosts. The aims of current study were to molecularly characterize $T$. foetus in the bovine host in the northwest region of USA and to phylogenetically analyze Tritrichomonas species among these various mammalian hosts using molecular data deposited in the GenBank.

\section{Results}

During the 2 years of sampling time, one positive sample was submitted from a herd in Blaine County, Montana and two from Butte County, South Dakota. There were 34 positive batches of samples from eight Wyoming counties, i.e., Carbon, Crook, Fremont, Hot Spring, Lincoln, Sweetwater, Unita, and Washakie (Table 1). Six batches of the 37 samples were submitted in frozen for PCR diagnosis. Among the 31 culture positive samples, five failed to multiply during passing in Diamond's media, resulting in a failure rate of $16.1 \%$.

The new primers targeted a $608 \mathrm{bp}$ fragment that enclosed the entire $347 \mathrm{bp}$ sequence amplified by the primers TFR3 and TFR4 being used in WSVL in diagnosing T. foetus infections [28]. In total, two and 14 isolates in South Dakota and Wyoming, respectively, were PCR amplified using the new primers, each yielded a single amplicon of the expected size. After DNA sequencing all PCR products had identical sequences. Two representative sequences minus primers, i.e., WY10 and SD1, were submitted to the GenBank. The accession numbers were MK250821 and MK250822, respectively. The new sequences borne $99.82 \%$ identity to M81842 (563/564) and $99.82 \%$ to AF466749 (540/541) of $T$. foetus, and $92.13 \%$ to JF927156 (527/572) of a Tritrichomonas sp. of an avian host by BLAST search.

We then performed a phylogenetic analysis of the two new rRNA sequences along with the entries of corresponding sequences of various trichomonads deposited in the GenBank. As showed in Fig. 1, trichomonad species such as Trichomonas vaginalis, T. gallinae, Pentatrichomonas hominis and Tetratrichomonas gallinarum were all well separated into branches of species individually and distanced from the cluster of Tritrichomonas spp., which included two species. A yet to be named Tritrichomonas sp. isolated from an avian host in Austria was closely yet distinctly separated from $T$. foetus. The latter were clearly divided into two closely-related clades. Clade I contained isolates originated in bovine, swine, squirrel monkey and human hosts in the geographical regions of North America, South America, Europe, Asia, Africa and Australia/Oceania. Clade II contained isolates of feline, canine and avian hosts in North America, South America, Europe and Australia/Oceania (Fig. 1).

Phylogenetic analysis of CP2 DNA sequences was also performed. Unfortunately, the phylogenetic tree was unrooted in this case due to lack of an outgroup of homologous sequences from other trichomonad species. Nevertheless, similar results as the rRNA analysis were obtained. Again, clade I included bovine, swine and human isolates in North America, South America, Europe, Asia, Africa and Australia/Oceania. Clade II consisted of feline and canine isolates of Europe and Australia. An isolate originated from Bolivian squirrel monkey was closely aligned with Clade II (Fig. 2).

\section{Discussion}

Tritrichomonas foetus is the causative agent of bovine trichomonosis, a widespread sexually transmitted disease of cattle in many geographical regions worldwide. The disease has been reported in six continents including North America, South America, Europe, Asia, Africa and Australia/Oceania. Although being eradicated in many EU countries the disease still exists in some foci where AI is not carried out. One example is Asturiana de la Montana, Northern Spain, where the prevalence of the parasite in bulls was 32\% in 2012 [4, 11, 13]. Interestingly, the disease was absent in cattle on St. Kitts, West Indies even though natural service of mating was the main reproductive method of the cattle populations on the island [3]. The disease was endemic in many US states including Alabama, California, Colorado, Florida, 
Table 1 Tritrichomonas foetus isolates included in this study

\begin{tabular}{|c|c|c|c|c|c|c|}
\hline Isolates & County, State & Sample tested & No positive $^{+}$ & Sampling date & Cultured & Sequenced \\
\hline $\mathrm{SD1}$ & Butte, SD & 4 & $1^{+}$ & $1 / 18 / 2011$ & + & + \\
\hline SD2 & Butte, SD & 21 & 1 & $4 / 12 / 2011$ & + & + \\
\hline WY1 & Unita, WY & 1 & $1^{+}$ & $1 / 24 / 2011$ & + & + \\
\hline \multirow[t]{2}{*}{ WY2 } & Unita, WY & 1 & 1 & $2 / 18 / 2011$ & + & + \\
\hline & Fremont & 2 & 1 & $2 / 22 / 2011$ & - & - \\
\hline WY3 & Unita, WY & 1 & $1^{+}$ & $3 / 28 / 2011$ & + & + \\
\hline \multirow[t]{2}{*}{ WY4-6 } & Unita, WY & 4 & $3^{+}$ & $4 / 8 / 2011$ & + & + \\
\hline & Carbon, WY & 48 & 2 & $4 / 15 / 2011$ & - & - \\
\hline WY7 & Hot Spring, WY & 73 & 1 & $4 / 20 / 2011$ & + & + \\
\hline WY8.1-8.2 & Carbon, WY & 18 & $7^{+\#}$ & $5 / 12 / 2011$ & + & + \\
\hline \multirow[t]{2}{*}{ WY9 } & Crook & 11 & $1^{+}$ & $5 / 13 / 2011$ & + & + \\
\hline & Hot Spring, WY & 25 & 2 & $5 / 23 / 2011$ & - & - \\
\hline WY10 & Hot spring, WY & 32 & 1 & $6 / 22 / 2011$ & + & + \\
\hline WY12-13 & Unita, WY & 2 & $2^{+}$ & $12 / 31 / 2011$ & + & + \\
\hline WY11 & Lincoln, WY & 39 & $1^{+}$ & $1 / 5 / 2012$ & + & + \\
\hline WY14 & Unita, WY & 1 & $1^{+}$ & $1 / 14 / 2012$ & + & - \\
\hline WY15 & Unita, WY & 51 & $1^{+}$ & $1 / 30 / 2012$ & + & - \\
\hline WY16 & Sweetwater, WY & 1 & $1^{+}$ & $1 / 28 / 2012$ & - & - \\
\hline WY17-18 & Lincoln, WY & 2 & $2^{+}$ & 2/7/2012 & + & - \\
\hline WY19.1-19.9 & Lincoln, WY & 109 & $13^{*}$ & $2 / 15 / 2012$ & - & - \\
\hline WY20.1-20.2 & Lincoln, WY & 30 & $2^{+}$ & $3 / 8 / 2012$ & + & - \\
\hline WY21 & Fremont, WY & 3 & $1^{+}$ & $4 / 3 / 2012$ & + & - \\
\hline WY22.1-22.2 & Washakie, WY & 14 & 3 & 10/17/2012 & + & - \\
\hline Wy23.1-23.2 & Washakie, WY & 80 & 2 & $11 / 29 / 2012$ & + & - \\
\hline WY24.1-24.2 & Washakie, WY & 36 & 2 & $12 / 4 / 2012$ & + & - \\
\hline \multirow[t]{5}{*}{ WY25 } & Washakie, WY & 95 & $1^{+}$ & $12 / 11 / 2012$ & + & - \\
\hline & Washakie, WY & 34 & 1 & $12 / 11 / 2012$ & - & - \\
\hline & Unita, WY & 5 & $2^{*}$ & 12/19/2012 & - & - \\
\hline & unknown, WY & 6 & $2^{*}$ & $1 / 3 / 2013$ & - & - \\
\hline & Sweetwater, WY & 12 & $4^{*}$ & $1 / 14 / 2013$ & - & - \\
\hline \multirow[t]{3}{*}{ WY26.1-26.6 } & Washakie, WY & 62 & 6 & $1 / 10 / 2013$ & + & - \\
\hline & Hot Spring, WY & 73 & 1 & $1 / 16 / 2013$ & + & - \\
\hline & Sweetwater, WY & 8 & $1^{*}$ & 1/19/2013 & - & - \\
\hline MT 1 & Blaine, MT & 55 & $2^{*}$ & $1 / 7 / 2013$ & - & - \\
\hline
\end{tabular}

${ }^{+}$: culture positive samples also confirmed by PCR

\#: Only two of seven sample were available for culture

*: Frozen samples were submitted for PCR only

Idaho, Kansas, Missouri, Montana, New Mexico, Nebraska, Nevada, Oklahoma, South Dakota, Utah and Wyoming [28]. In an effort to control the disease many US states including all states west of the Mississippi River except Minnesota along with Mississippi, Alabama, Georgia, Tennessee and Hawaii have state rules and regulations on bovine trichomonosis. In this study available samples of positive $T$. foetus bulls diagnosed by WSVL between January 2011 and January 2013 were included, which covered samples from South Dakota, Montana and Wyoming. One shortcoming of the study is that prevalence of $T$. foetus could not be calculated because the study did not cover all herds in these states. Nevertheless, one of our earlier studies showed that annual prevalence of Wyoming bulls from year 2000 to 2010 was between 0.21 and $1.69 \%$. Furthermore, numbers of positive bulls between 2006 to 2010 were annually recorded as 57, 50, 45, 98 and 17, respectively [28]. This 


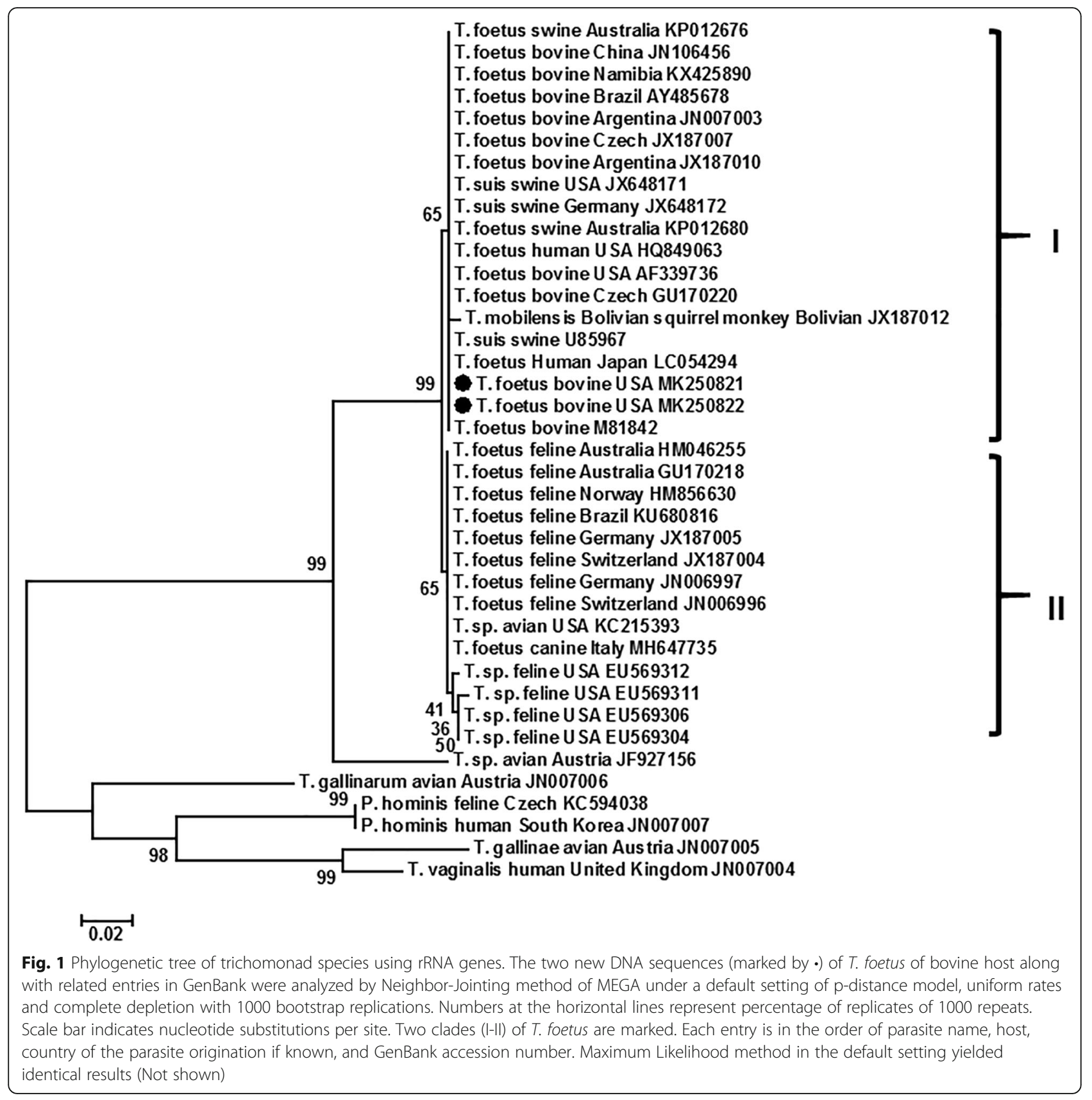

current study showed positive bulls in Wyoming in 2011 and 2012 were 23 and 47, respectively. Collectively, our data showed the least numbers of positive bulls in years 2010 and 2011 over a decade period of time since 2000 when state bovine trichomonosis rules started to be enforced. However, number of the positive bulls was more than doubled in the year 2012 compared to the two previous years, which might be caused by complacency of some cattle farmers and should raise some concerns. A well-designed epidemiological study needs to be carried out to address what caused this recurrence if the trend continues.
Additionally, T. foetus had been routinely found in the domestic cat in 21 countries in North America, South America, Europe, Asia and Australia/Oceania [30, 31]. However, it was not detected in the cat populations on St. Kitts, West Indies by culturing and PCR [31]. The feline strain differs from the bovine strain by one base pair in the ITS-2 sequence $[25,29]$. In addition, there were some differences in other genes. Majority of these differences were less than $1 \%$ except cysteine protease 2 and 6 , which were 3.3 and $1.9 \%$, respectively [18, 29]. In addition, other Tritrichomonas spp. had been described in various mammals. One example is $T$. suis that is 


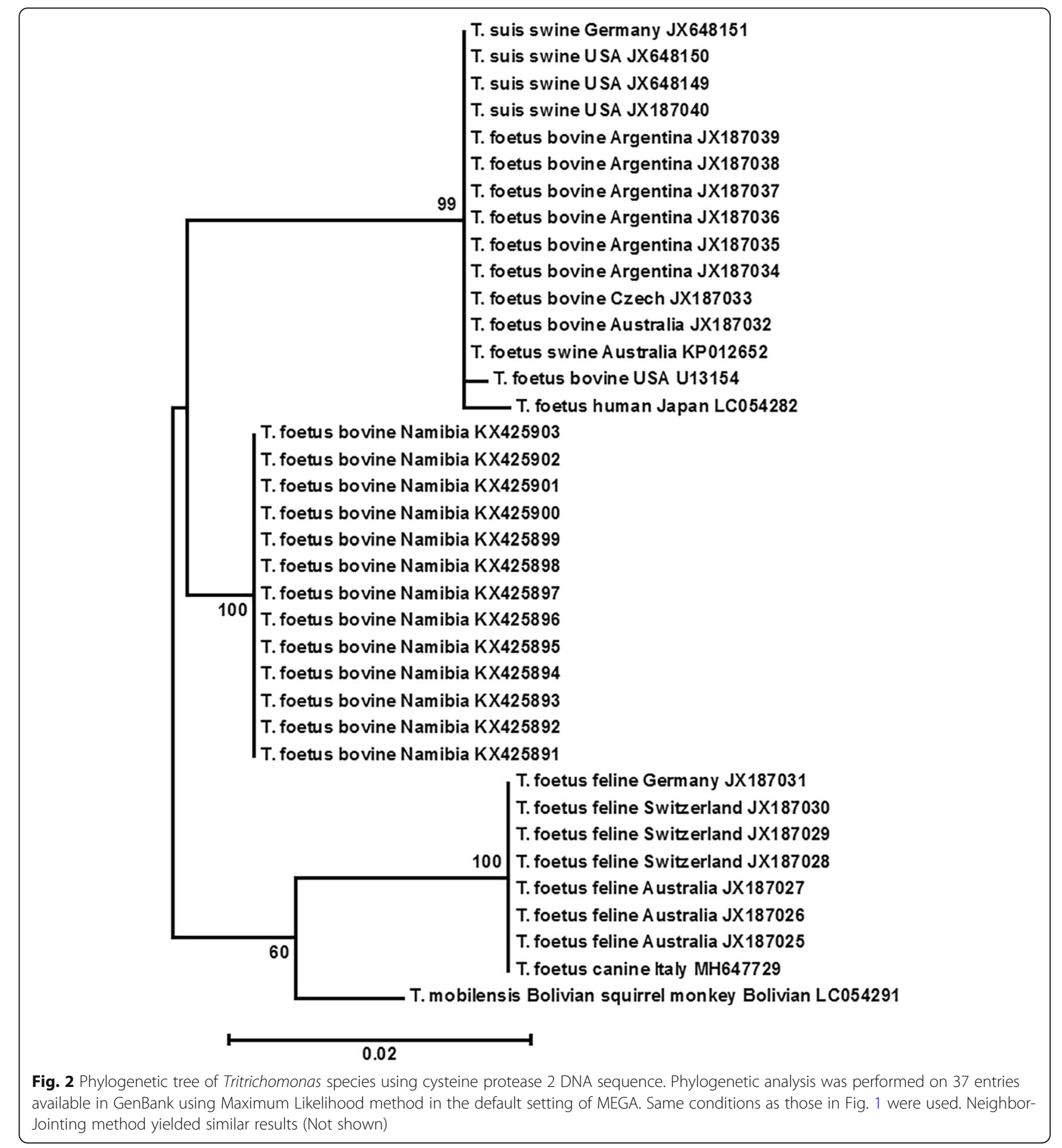

commonly found in nasal cavity, stomach, cecum, and colon of swine hosts as a commensal, and molecular data had suggested this species is a synonym of $T$. foetus $[19,20]$. Sequence analysis of multiple genes also concluded that $T$. suis was synonymous to the bovine isolate of $T$. foetus. The bovine, feline and swine isolates should be given the name of $T$. foetus [18]. Another example is T. mobilensis of Bolivian squirrel monkeys, which was similar to T. foetus even at the ultrastructural level [12]. Our phylogenetic analysis on rRNA and CP2 DNA sequences of representative isolates around the world had clearly showed two very close clades of $T$. foetus (Figs. 1 and 2). Clade I included bovine isolates including the two new ones from South Dakota and Wyoming, swine isolates, and human isolates. Clade II included feline and canine isolates. The Bolivian squirrel monkey isolate was 
inconsistent. It was in clade I and II in rRNA and CP2 analysis, respectively (Figs. 1 and 2). The avian isolate was in the Pacific Coast band-tailed pigeon (Patagioenas fasciata monilis) from California and was considered due to coprophegia of infected cat feces by the pigeon [5]. The domestic dog had been infrequently found infected with $T$. foetus in USA, China and Italy. The prevalence was $0.6 \%(2 / 315)$ in Anhui Province and Zhejiang Province, China among the dogs visiting veterinary clinics with or without diarrhea and $2.6 \%$ in dogs with diarrhea in USA [9, 23]. In a survey of shelter dogs in Italy from April to September 2017, 1.7\% (1/59) dogs were found positive with $T$. foetus "feline isolate" by microscopy, PCR and DNA sequencing [7]. In a survey of 245 kennel puppies with or without diarrhea in France in $2009,15.8 \%(34 / 215)$ were positive for fecal trichomonads by microscopy. Nevertheless, PCR and DNA sequencing showed 26 of the 34 samples were $P$. hominis positive whereas none were positive for $T$. foetus [6]. It is very likely that $T$. foetus feline isolate may be a parasite of canine host that results in diarrhea in infected dogs. However, this needs to be further confirmed. Collectively, Tritrichomonas spp. in mammalian hosts including cattle, cat, pig, dog, human and squirrel monkey are all considered as $T$. foetus unless otherwise proven with new molecular data in the future. Nevertheless, a Tritrichomonas sp. found in the intestine of a common quail (Coturnix coturnix) was distantly clustered to the two clades of T. foetus (Fig. 1). The rRNA sequences showed approximately $95 \%$ identity to those of T. foetus [14]. Whether this species is the same one as the previously described T. gigantica in the cecum of the same species of bird in India [15] needs to be determined by molecular studies.

\section{Conclusion}

Clinic isolates of T. foetus in cattle populations in South Dakota, Montana, and Wyoming were molecularly characterized by PCR and DNA sequencing of rRNA sequences. Phylogenetic analysis on rRNA and CP2 DNA sequences showed two clades of $T$. foetus. Clade I consisted of these new isolates along with other bovine isolates, swine isolates, and human isolate whereas clade II contained feline and canine isolates. All isolates harbored by these mammals were T. foetus.

\section{Methods}

\section{Clinical isolates}

Between January 2011 and January 2013 preputial samples from bulls collected at cattle farms and subsequently submitted to the Wyoming State Veterinary Laboratory (WSVL) by various individual veterinarians were included in this study. All bulls in reproduction were required an annual $T$. foetus test by state rules.
WSVL employed both culturing in Diamond's medium and conventional gel-PCR for clinical diagnosis of $T$. foetus infection in cattle [28]. Cultures were routinely discarded and destroyed according to SOP of WSVL after a diagnosis was made. However, all positive cultures were saved and passed on to a research laboratory for the current study followed diagnosis between January 2011 and January 2013. No identities of farmers, nor the tag numbers of $T$. foetus positive cattle were revealed. Consequently, a waiver was granted for the current study by the Institutional Animal Care and Use Committee (IACUC) of the University of Wyoming.

\section{Cell culture}

The original clinical cultures were transferred from WSVL to a research lab in a cooler with its temperature being maintained at $37^{\circ} \mathrm{C}$ with warm water. The transferring between buildings on campus took a maximum of $30 \mathrm{~min}$. They were cultured immediately in Diamond's medium as previously described [27]. Briefly, the original clinical cultures were diluted in three to four $50 \mathrm{ml}$ conical tubes filled with $50 \mathrm{ml}$ Diamond's medium at a starting cell density of $1 \times 10^{4}$ cells $/ \mathrm{ml}$ and were incubated vertically in $37^{\circ} \mathrm{C}$ without agitation. Cell growth was monitored daily using a hemocytometer, and cells were harvested at day 3-4 of culture when they reached approximately $5 \times 10^{6}$ cells $/ \mathrm{ml}$ by centrifugation at $800 \times g$ for $10 \mathrm{~min}$ at $4{ }^{\circ} \mathrm{C}$. Cell pellets were stored in $-20^{\circ} \mathrm{C}$ after being washed twice in Hank's Balanced Salt Solution (HBSS, ThermalFisher Scientific, Carlsbad, CA) by same centrifugation. For all isolates included in the current study only the first passaged cells were used in order to minimize biased selection of population of $T$. foetus cells that favored the cultural conditions.

\section{PCR and DNA sequencing}

Cell pellets were thawed at room temperature and were lysed at $37^{\circ} \mathrm{C}$ for $1 \mathrm{~h}$ in $1.0 \%$ SDS supplemented with $0.1 \mathrm{mg} / \mathrm{ml}$ protease $\mathrm{K}$. DNA was extracted with phenol/ chloroform/isoamyl alcohol mix in a ratio of 25:24:1 (Sigma, St Louis, MO) after being treated with $0.1 \mathrm{mg} /$ $\mathrm{ml}$ RNAse at $37^{\circ} \mathrm{C}$ for $10 \mathrm{~min}$, and was quantified and qualified by spectrophotometry (NanoDrop, ThermalFisher Scientific). PCR primers were designed from the sequence of rRNA genes of $T$. foetus bovine isolate (GenBank accession number: M81842). The primers (forward 5' -CCCTTGTAAATGCGTGTCAACAG-3'; reverse 5'-CGAACTCTACTCTCTTCGGTCGCACT$3^{\prime}$ ) were synthesized by IDT (Coralville, IA). The targeted DNA sequence of $608 \mathrm{bp}$ included partial small subunit rRNA, internal transcribed spacer (ITS) 1, 5S rRNA, ITS 2, and partial large subunit rRNA. A thermal cycle consisting of initial $95^{\circ} \mathrm{C} 5 \mathrm{~min}, 35$ cycles of $95^{\circ} \mathrm{C}$ $30 \mathrm{~s}, 64^{\circ} \mathrm{C} 30 \mathrm{~s}$, and $72{ }^{\circ} \mathrm{C} 1 \mathrm{~min}$ followed by $72{ }^{\circ} \mathrm{C} 10 \mathrm{~min}$ 
was carried out in a Veriti ${ }^{\text {im }}$ 96-Well Thermal Cycler (ThermalFisher Scientific) for hot start PCR. PCR products were revealed on $1.2 \%$ agarose gel with TrackIt ${ }^{\mathrm{mi}}$ 100 DNA ladder (Invitrogen) and were purified afterwards using QIAquick PCR Purification Kit (QIAGEN, Germantown, MD). Purified PCR products were directly sequenced in both directions using $25 \mathrm{ng}$ DNA and one PCR primer in the in-house sequencing facility of the University of Wyoming (Nucleic Acid Exploration Facility). Occasionally ambiguous nucleotides were manually read out from sequence chromatograph. A unanimous sequence was generated for each DNA sample using sequences of both directions.

\section{Phylogenetic analysis of rRNA and cysteine protease (CP) 2 genes}

Keywords Tritrichomonas and rRNA were used to search nucleotide database of the National Center for biotechnology information (NCBI), which yielded 255 entries (https://www.ncbi.nlm.nih.gov/nuccore/?cmd= HistorySearch\&querykey=7, accessed December 10, 2018). All entries that contained ITS sequences were manually downloaded and a phylogenetic analysis was performed along with the two new sequences generated in the current study and deposited into GenBank using MEGA software (version 5.2) [21]. Representative entries were included in the phylogenetic analysis if multiple sequences were originated from same host and in the same origin of country to avoid overwhelming a phylogenetic tree with too many entries. Both neighbor-jointing and maximum likelihood methods were performed under default conditions of the MEGA software

Similarly keywords Tritrichomonas Protease and CP2 were used to search NCBI database Resulting in 36 entries (https://www.ncbi.nlm.nih.gov/nuccore?term $=(($ Tritrichomonas)\%20AND\%20protease)\%20AND\%20CP2 Accessed January 17 2019). An additional entry was added by BLAST. Phylogenetic analysis was performed using neighbor-jointing and maximum likelihood methods under default conditions of the MEGA software.

\section{Abbreviations}

Al: Artificial insemination; CP: Cysteine protease; EU: European Union; HBSS: Hank's Balanced Salt Solution; ITS: Internal transcribed spacer; UK: United Kingdom; USA: United States of America; WSVL: Wyoming State Veterinary Laboratory

\section{Acknowledgments}

We are grateful to Katherine D. Bardsley of the Wyoming State Veterinary Laboratory for providing the T. foetus clinical isolates used in the current study.

Consent to publication

Not applicable.

\section{Authors' contributions}

$A D$ and $C Y$ conceived the study and analyzed the data. YJ performed the experiments. CY drafted the manuscript. All authors read and approved the final version of the manuscript.

\section{Funding}

The study was supported in part by the USDA Hatch fund WYO-463-11 (CY) and Wyoming Livestock Board MOU (CY). Publication cost of this article was provided by the Center One of Ross University School of Veterinary Medicine. The funding source played no roles in the design of the study and collection, analysis, and interpretation of data and in writing the manuscript.

\section{Availability of data and materials}

All data generated or analyzed during this study are included in this published article. DNA sequences are submitted to GenBank with accession numbers of MK250821 and MK250822.

Ethics approval and consent to participate Not applicable.

\section{Competing interests}

The authors declare that they have no competing interests.

\section{Author details}

${ }^{1}$ Department of Veterinary Sciences, University of Wyoming, Laramie, WY 82070, USA. ${ }^{2}$ Present Address: Division of Pharmacoepidemiology and Pharmacoeconomics, Department of Medicine, Brigham and Women's Hospital and Harvard Medical School, Boston, MA 02115, USA. ${ }^{3}$ Zhejiang Provincial Key Laboratory of Preventive Veterinary Medicine, Institute of Preventive Veterinary Medicine, College of Animal Sciences, Zhejiang University, Hangzhou 310058, China. ${ }^{4}$ Department of Biomedical Sciences and One Health Center for Zoonoses and Tropical Veterinary Medicine, Ross University School of Veterinary Medicine, P.O. Box 334, Basseterre, St. Kitts and Nevis.

Received: 4 June 2019 Accepted: 31 December 2019

Published online: 10 January 2020

\section{References}

1. Alexander $\mathrm{Gl}$. An outbreak of bovine trichomoniasis in Queensland and its control. Aus Vet J. 1953;29:61-6.

2. Clark BL, Parsonson IM, Dufty JH. Letter: infection of bulls with Tritrichomonas foetus through mating with infected heifers. Aust Vet J. 1974; 50:180.

3. Coker KE, Lim JJ, Schleisman RL, Vosloo C, French HM, Samper JC, Callanan JJ, Gilbert RO, Sithole F, Yao C, Chapwanya A. Freedom from Tritrichomonas foetus infection in cattle in St. Kitts. Trop Anim Health Prod. 2018:50:1171-3.

4. Collantes-Fernández E, Mendoza-Ibarra JA, Pedraza-Díaz S, Rojo-Montejo S, Navarro-Lozano V, Sánchez-Sánchez R, Ruiz-Santa-Quiteria JA, Ortega-Mora LM, Osoro K. Efficacy of a control program for bovine trichomonosis based on testing and culling infected bulls in beef cattle managed under mountain pastoral systems of northern Spain. Vet J. 2014;200:140-5.

5. Girard YA, Rogers KH, Woods LW, Chouicha N, Miller WA, Johnson CK. Dualpathogen etiology of avian trichomonosis in a declining band-tailed pigeon population. Infect Genet Evol. 2014:24:146-56.

6. Grellet A, Brunopolack, Feugier A, Boucraut-Baralon C, Grandjean D, Vandewynckel L, Cian A, Meloni D, Viscogliosi E. Prevalence, risk factors of infection and molecular characterization of trichomonads in puppies from French breeding kennels. Vet Parasitol. 2013;197:418-26.

7. latta R, Buonfrate D, Paradies P, Cavalera MA, Capogna A, larussi F, Slapeta J, Giorli G, Trerotoli P, Bisoffi Z, Otranto D. Occurrence, diagnosis and followup of canine strongyloidiosis in naturally infected shelter dogs. Parasitology. 2019;146:246-52.

8. Jin Y, Schumaker B, Logan J, Yao C. Risk factors associated with bovine trichomoniasis in beef cattle identified by a questionnaire. J Med Microbiol. 2014;63:896-902.

9. $\quad$ Li W-C, Wang K, Zhang W, Wu J, Gu Y-F, Zhang X-C. Prevalence and molecular characterization of intestinal trichomonads in pet dogs in East China. Korean J Parasitol. 2016;54:703-10.

10. Lun ZR, Chen XG, Zhu XQ, Li XR, Xie MQ. Are Tritrichomonas foetus and Tritrichomonas suis synonyms? Trends Parasitol. 2005;21:122-5. 
11. Mendoza-Ibarra JA, Pedraza-Diaz S, Garcia-Pena FJ, Rojo-Montejo S, RuizSanta-Quiteria JA, San Miguel-Ibanez E, Navarro-Lozano V, Ortega-Mora LM, Osoro K, Collantes-Fernandez E. High prevalence of Tritrichomonas foetus infection in Asturiana de la Montana beef cattle kept in extensive conditions in northern Spain. Vet J. 2012;193:146-51.

12. Midlej V, Pereira-Neves A, Kist LW, Bogo MR, Benchimol M. Ultrastructural features of Tritrichomonas mobilensis and comparison with Tritrichomonas foetus. Vet Parasitol. 2011;182:171-80.

13. Miro G, Hernandez L, Montoya A, Arranz-Solis D, Dado D, Rojo-Montejo S, Mendoza-Ibarra JA, Ortega-Mora LM, Pedraza-Diaz S. First description of naturally acquired Tritrichomonas foetus infection in a Persian cattery in Spain. Parasitol Res. 2011;109:1151-4.

14. Mostegl MM, Richter B, Nedorost N, Maderner A, Dinhopl N, Kubber-Heiss A, Weissenbock $\mathrm{H}$. Identification of a putatively novel trichomonad species in the intestine of a common quail (Coturnix coturnix). Vet Parasitol. 2012;183: 369-72.

15. Navarathnam ES. A new species of Tritrichomonas from the caecum of the bird Coturnix coturnix Linneaus. Riv Parassitol. 1970;31:9-14.

16. Parsonson IM, Clark BL, Dufty JH. Early pathogenesis and pathology of Tritrichomonas foetus infection in virgin heifers. J Comp Pathol. 1976;86:59-66.

17. Skirrow S. Identification of trichomonad-carrier cows. J Am Vet Med Assoc. 1987:191:553-4.

18. Slapeta J, Muller N, Stack CM, Walker G, Lew-Tabor A, Tachezy J, Frey CF. Comparative analysis of Tritrichomonas foetus (Riedmuller, 1928) cat genotype, T. foetus (Riedmuller, 1928) cattle genotype and Tritrichomonas suis (Davaine, 1875) at 10 DNA loci. Int J Parasitol. 2012; 42:1143-9.

19. Sun Z, Stack C, Slapeta J. Sequence differences in the diagnostic region of the cysteine protease 8 gene of Tritrichomonas foetus parasites of cats and cattle. Vet Parasitol. 2012;186:445-9.

20. Tachezy J, Tachezy R, Hampl V, Sedinova M, Vanacova S, Vrlik M, Van Ranst M, Flegr J, Kuldaa J. Cattle pathogen Tritrichomonas foetus (Riedmuller, 1928) and pig commensal Tritrichomonas suis (Gruby \& Delafond, 1843) belong to the same species. J Eukaryot Microbiol. 2002;49:154-63.

21. Tamura K, Peterson D, Peterson N, Stecher G, Nei M, Kumar S. MEGA5: molecular evolutionary genetics analysis using maximum likelihood, evolutionary distance, and maximum parsimony methods. Mol Biol Evol. 2011;28:2731-9.

22. Taylor MA, Marshall RN, Stack M. Morphological differentiation of Tritrichomonas foetus from other protozoa of the bovine reproductive tract. Br Vet J. 1994;150:73-80.

23. Tolbert MK, Leutenegger CM, Lobetti R, Birrell J, Gookin JL. Species identification of trichomonads and associated coinfections in dogs with diarrhea and suspected trichomonosis. Vet Parasitol. 2012;187:319-22.

24. Walden HS, Dykstra C, Dillon A, Rodning S, Givens D, Bird R, Newton J, Lindsay D. A new species of Tritrichomonas (Sarcomastigophora: Trichomonida) from the domestic cat (Felis catus). Parasitol Res. 2013;112: 2227-35.

25. Yao C. Opportunistic human infections caused by tritrichomonas species: a mini-review. Clin Microbiolo Newsl. 2012;34:127-31.

26. Yao C. Diagnosis of Tritrichomonas foetus-infected bulls, an ultimate approach to eradicate bovine trichomoniasis in US cattle? J Med Microbiol. 2013;62:1-9

27. Yao C. Tritrichomonas foetus infections in female beef cattle with abortion in Wyoming. USA JMM Case Reports. 2015;2(2):1-5. https://doi.org/10.1099/ jmmcr.0.000028.

28. Yao C, Bardsley KD, Litzman EA, Hall ML, Davidson MR. Tritrichomonas foetus infection in beef bull populations in Wyoming. J Bacteriol Parasitol. 2011;2:117.

29. Yao C, Ketzis JK. Aberrant and accidental trichomonad flagellate infections: rare or underdiagnosed? Trans R Soc Trop Med Hyg. 2018;112:64-72.

30. Yao C, Koster L. Tritrichomonas foetus infection, a cause of chronic diarrhea in the domestic cat. Vet Res. 2015;46:35.

31. Yao C, Köster L, Halper B, Dundas J, Nair R. Failure to detect Tritrichomonas foetus in a cross-sectional survey in the populations of feral cats and owned outpatient cats on St Kitts, West Indies. JFMS Open Rep. 2018;4(1): 2055116918782584.

\section{Publisher's Note}

Springer Nature remains neutral with regard to jurisdictional claims in published maps and institutional affiliations.

\section{Ready to submit your research? Choose BMC and benefit from:}

- fast, convenient online submission

- thorough peer review by experienced researchers in your field

- rapid publication on acceptance

- support for research data, including large and complex data types

- gold Open Access which fosters wider collaboration and increased citations

- maximum visibility for your research: over $100 \mathrm{M}$ website views per year

At BMC, research is always in progress.

Learn more biomedcentral.com/submissions 